\title{
Prevalence of Intestinal Parasitic Infection and Malnutrition in Enugu Urban and Suburban Area
}

\author{
Unachukwu MN' ${ }^{1}$, Nwakanma $C^{2}$ \\ ${ }^{1}$ Dr Marian Unachukwu, Senior Lecturer, Department of Biological Sciences, Faculty of Natural and Applied Sciences, \\ Godfrey Okoye University, Enugu State, Nigeria. ${ }^{2}$ Dr Chioma Nwakanma, Lecturer I, Department of Environmental \\ Management and Toxicology, College of Natural Resources and Environmental Management, Michael Okpara University \\ of Agriculture, Umudike, Abia State. Nigeria.
}

Address for correspondence: Dr Chioma Nwakanma, Email: dr.nwakanmac@gmail.com

\begin{abstract}
Introduction: The prevalence of intestinal parasitic infections and malnutrition among school children in urban and suburban of Enugu metropolis was carried out. Methods: Anthropometric measurements consisting of weight, head circumference and mid arm circumference were measured. Weight for age, head and mid arm circumference were used as indicators to determine the nutritional status (malnutrition). Examination of stool specimens was done using direct wet mount examination and concentration techniques. The parasitosis and malnutrition was studied in 98 (40 urban and 58 suburban) school children aged 1 to 12 years. Results: The overall prevalence (positive) of intestinal parasites in this study was 38(38.8\%), while 60(61.2\%) were absent (negative). The prevalence of infection was significantly higher among the suburban (\%) children than among the urban (\%) children. The prevalence of Ascaris lumbricoides 11(27.5\%) was higher in suburban than in urban Ascaris lumbricoides 5(12.5\%) than all other parasites encountered from suburban and urban area respectively. The study does not really show a significant association between nutritional indicators and intestinal parasitic infection but shows a slight association to Ascariasis and hookworm infection. Conclusion: This study shows that there is a slight improvement in the level of malnutrition, hygiene and sanitation in Enugu metropolis. Since intestinal parasitic infections are associated with malnutrition, controlling these parasites would increase the physical development and wellbeing of the affected children.
\end{abstract}

Keywords: Ascariasis, Schistosomiasis, Anthropometric Measurement, Environmental conditions.

\section{Introduction}

An estimated global infection rate for some parasites has primarily been attributed to the appalling unhygienic and environmental condition, poverty and over - dispersion of parasites and disease are immediate causes of malnutrition and deaths of young children. They reinforce each other synergistically [1]. In developing countries, poor nutrition, overcrowding and climatic conditions favor the development and survival of the parasites and some of the factors contribute to the high level of intestinal parasites transmission. School Children ( 1 - 12 years) carry the heaviest burden of the associated morbidity due to their dirty habits of playing or handling of infected soils, eating with soiled hands, unhygienic toilet practices, drinking and eating of contaminated water and food. As children are most at

Manuscript received: $14^{\text {st }}$ Oct 2014

Reviewed: $19^{\text {th }}$ Oct 2014

Author Corrected: $6^{\text {th }}$ Nov 2014

Accepted for Publication: $7^{\text {th }}$ Nov 2014 risk at an age when they are both growing and learning, Parasitic infections potentially threatens a child's overall physical and psychological development and may cause malnutrition [2]. Globally, it is estimated that among preschool age children in developing countries 183 million are under weight, 226 million are stunted and 67 million wasted [3]. There are documented reports implicating intestinal parasitic infection with poor nutritional status (malnutrition) in children between 1 12 years (school age). Amoebiasis, giardiasis, Ascariasis, hookworm infection and Trichuriasis are among the most common intestinal parasitic infection worldwide though there are others. These infections are associated with decreased child growth, low plasma vitamin A, loss of weight, chronic blood loss, iron deficiency, anemia, diarrhea and stunted growth. Alteration of the normal gastro intestinal flora by intestinal parasites has been found to be associated with diarrhea, a major cause of 
childhood morbidity and mortality in developing countries. Apart from causing mortality and morbidity, infection with intestinal parasites has been associated with stunting of linear growth, physical weakness and low educational achievement in school children [4]. In Nigeria, Schistosomiasis, parasitic protozoan and soil transmitted helminth infections are important parasitic diseases. The highest transmission levels of Schistosomiasis occur in the northern regions [5]. Abnormalities of intestinal mal-absorption contribute to nutritional deficiency [6]. Nutrition plays a major role in maintaining health and malnutrition appears and general ill - health [7]. The infection in children can interfere with growth and development. This study therefore aims to fill the gap in knowledge by investigating the parasitic infections and malnutrition among the school children (1 -12 years) in Enugu metropolis. The study was conducted to determine the prevalence of intestinal parasitic infection and malnutrition, sanitation, hygiene in children of urban and sub urban of Enugu metropolis. Intestinal parasitic infections (IPI) constitute a global health burden causing clinical morbidity in 450 million people; many of the women at reproductive age and children in developing countries [8]. Indeed, IPIs, mostly helminthes, have been linked with an increased risk for nutritional anemia, protein - energy malnutrition and growth deficits in children, low pregnancy weight gain and intrauterine growth retardation followed by low birth weight $[9,10]$. Intestinal helminthes infestations are most common among school age children and they tend to occur in his intensity in this age group [11]. Several environmental and socio-economic factors have been identified to be responsible for the continued persistence of intestinal parasites in children; some of these include poor sanitary condition, unhygienic practices, absence of portable water, poor housing and poverty $[12,13]$. The school environment has therefore emerged as epidemiological foci in childhood parasitism $[14,15,16]$. Low socio-economic state and poor sanitation coupled with low educational rates of parents, particularly the mothers are the main causes influencing the transmission and distribution of the infestation [17]. In addition, environmental demographic and health related behaviors also influence infection. The morbidity of soil transmitted helminthes is the greatest among children of school age and may have an adverse effect on growth [18]. Malnutrition is a medical condition that results from eating a diet in which certain nutrients are lacking, in excess (too high in take), or in the wrong proportions. Children can receive the nutritious foods, but poor environmental sanitation can lead to diarrhea and other childhood infections which limit their ability to absorb nutrients from the food, resulting in a vicious cycle of malnutrition and disease. Nutrition plays a major role in maintaining health and malnutrition appears to generate vulnerability to a wide of diseases and general ill-health [19]. While low and poor food intake is the major recognized causes of protein - energy malnutrition in children worldwide, giardiasis could be implicated in influencing this condition. It is common for acute symptomatic individuals to present with diarrhea or clinical manifestations of mal-absorption. The infection in children can interfere with growth and development. Growth failure is associated with increased morbidity and mortality in children and it is estimated that as many as 182 million children in developing countries of the world are affected [20]. Although the etiology of growth failure is multifactorial, malnutrition and repeated infections in children have been documented as causative agents, among which Giardia lamblia is a hallmark cause [14].

\section{Materials and Methods}

This study was carried out between April and May 2014. The study area is Enugu, the capital of Enugu State. It is located at the foot of Udi hill with a height of about 210 meters above Sea level. The late dry season is in February and March when the relative humidity's is low but the temperature begins to rise. The wet season commences in April with a few showers in March, until October. Some little gift was given to them (pupils and teachers) for appreciation. Six (6) randomly selected schools comprising of Nursery and Primary class in Urban Area of Enugu in Nigeria were included in study. A total of 120 children (60 urban and 60 suburban) of the six different schools were initially enrolled, samples both boys and girls with ages ranging from $1-12$ years were selected from each school. The sum total of 98 (ninety eight) samples were collected from the whole 120 that was initially enrolled. Well labeled, clean, dry sterile screw capped container were given to the children in which their stool samples were to be collected. The procedure of introducing the stool into the container was explained and demonstrated to pupils with the help and the unexpected assistance of their class teachers. They were given a day before collecting the sample from them. The stool samples collected were all transported to Godfrey Okoye University microbiology laboratory for parasitological examination and reporting. Anthropometric measurements of weight for age (WA), hand and head circumference were used (according to WHO guide lines [20] to assess the nutritional status of the children. The subjects were weighted barefooted and in light clothing (school uniform) on a scale accurate to $0.1 \mathrm{~kg}$. The scale was standardized before use. Hand and head circumference were measured to the nearest $1 \mathrm{~cm}$. As the measurement was going on, the age, sex and class 
of the subject was obtained from the class teacher's register and recorded on a recording book. Then the result of the whole measurement (weight, head and hand circumference) were equally recorded. The samples collected on each occasion were all examined in Godfrey Okoye University Microbiology Laboratory without preservation. Two methods were used for the examination of the sample and they include; direct wet mount and sedimentation method (formol - ether concentration technique). But before then, the stool was first examined macroscopically to identify the presence of blood, mucus, pus, worm, colour and the consistency of the stool (i.e. whether formed, semi-formed, and unformed/watery stool). A drop of fresh physiological saline was placed on one end of a clean slide and a drop of iodine lugol's solution on the other end when stool was semi-formed or formed but unformed, normal saline was not added. Then wooden stick was used to mix a small amount of the sample, about $2 \mathrm{mg}$, with the above mentioned reagents. Thin preparation was made before covering with a cover slip. It was placed on the microscope to examine the entire saline preparation for larvae, ciliates, helminth eggs, cysts and oocysts using 10x objective with the condenser iris closed sufficiently to give good contrast. 40x objectives were also used in the detection and identification of egg, cysts and oocysts. The entire stool samples were examined using this method. $2 \mathrm{ml}$ of stool sample was placed in a well labeled centrifuge tube using plastic pipette. $7 \mathrm{ml}$ of $10 \%$ formalin and $3 \mathrm{ml}$ of ethyl acetate was added in the same tube, it was well mixed and opened to let the vapour out then closed quickly and mixed again. The tube was centrifuged at $750-1000 \mathrm{~g}$ (approximately $3000 \mathrm{rpm}$ ) for 1 minute, after which wooden stick was used to loosen the layer of faecal debris from the side tube and inverted the tube discarding the supernatant leaving the sediment or deposit in the tube. A drop of normal saline was added on a clean slide; it was mixed with a drop of the sediment using wooden stick, and then covered with cover slip. The slide was fixed on the microscope to see larvae using 10x objective and protozoa cyst and trophozoites using $40 \mathrm{x}$ objectives. It was not done for all the stool samples but for the positive cases. Diagnosis was based on the identification of helminth ova and protozoan cyst in the sample during microscopic analysis.

\section{Results}

A total of 120 children (60 urban and 60 suburban) of six (6) different nursery and primary schools in Enugu state were initially enrolled, but the result presented below are the data for 98 children (40 urban and 58 suburban) who returned suitable stool specimen after their anthropometric data were collected. There were 17 boys and 23 girls for the urban areas and 38 males and 20 females for the suburban areas. The subjects were aged between 1 and 12 years. The incidence of the 4 (four) identified parasites in this study are considerable low in Wesley nursery school Akpasha suburban area in Enugu State environment.

Table 1: Prevalence of Intestinal Parasites among children in urban and suburban Nursery and Primary School in Enugu State environment

\begin{tabular}{|c|c|c|c|}
\hline Parasite & Urban Children & Suburban Children & All Children \\
\hline & NO (\%) infected & No $(\%)$ infected & No $(\%)$ \\
\hline & $\mathrm{n}=40$ & $\mathrm{n}=58$ & $\mathrm{n}=98$ \\
\hline A. Lumbricoides & $5(12.5)$ & $11(27.5)$ & $16(40.0)$ \\
\hline Hookworm & $2(5.0)$ & $8(20.0)$ & $10(25.0)$ \\
\hline G. Lamblia & $3(7.5)$ & $3(7.5)$ & $6(15.0)$ \\
\hline T. trichiura & $1(2.5)$ & $2(5.0)$ & $3(7.5)$ \\
\hline E. histolytica & $2(5.0)$ & $1(2.5)$ & $3(7.5)$ \\
\hline Subtotal & $13(32.5)$ & $25(43.1)$ & $38(38.8)$ \\
\hline Absent & $27(67.5)$ & $33(56.8)$ & $70(61.2)$ \\
\hline Total & 40(100.0) & 33(56.8) & 70(61.2) \\
\hline \multicolumn{4}{|c|}{ No of intestinal Parasite per child (Polyparasitism) } \\
\hline \multirow[t]{2}{*}{ Parasite } & Urban Children & Suburban Children & All Children \\
\hline & $\mathrm{n}=40$ & $\mathrm{n}=58$ & $\mathrm{n}=98$ \\
\hline 1 & $14(35.0)$ & $23(40.0)$ & $37(38.0)$ \\
\hline 2 & $6(15.0)$ & $9(16.0)$ & $15(15.3)$ \\
\hline$>=3$ & $2(5.0)$ & $5(9.0)$ & $7(7.1)$ \\
\hline
\end{tabular}


It is obvious that from Table 1, percentage of children with more than one intestinal parasite were more in the Suburban (40.0) than Urban children (35.0). A lumbricus was higher in number and in Suburban children(27.5), while T. trichiura and E. histolytica was lower in number at (2.5) respectively. Total numbers of infected children were higher in Suburban (43.1) than Urban children (32.5).

Table 2: The age -specific prevalence of intestinal parasite among 40 Urban children.

\begin{tabular}{|l|l|l|l|l|}
\hline Age (years) & $1-3$ & $4-6$ & $7-9$ & $10-12$ \\
\hline $\begin{array}{l}\text { No of children } \\
\text { investigated }\end{array}$ & 5 & 19 & 10 & 6 \\
\hline No. infected with & & & & \\
\hline A. lumbricoides & $1(20.0)$ & $2(11.0)$ & $2(20.0)$ & $0(0.0)$ \\
\hline Hook worm & $0(0.0)$ & $1(5.3)$ & $1(10.0)$ & $0(0.0)$ \\
\hline G. lamblia & $0(0.0)$ & $2(11.0)$ & $0(0.0)$ & $1(16.7)$ \\
\hline T. trichiura & $0(0.0)$ & $1(5.3)$ & $0(0.0)$ & $0(0.0)$ \\
\hline E. histolytica & $1(20.0)$ & $0(0.0)$ & $1(10.0)$ & $0(0.0)$ \\
\hline Sub total & $2(40.0)$ & $6(31,6)$ & $4(40.0)$ & $1(16.7)$ \\
\hline Absent & $3(60.0)$ & $13(68.4)$ & $6(60.0)$ & $5(83.3)$ \\
\hline Total & $\mathbf{5 ( 1 0 0 . 0 )}$ & $\mathbf{1 9}(\mathbf{1 0 0 . 0})$ & $\mathbf{1 0}(\mathbf{1 0 0 . 0})$ & $\mathbf{6 ( 1 0 0 . 0 )}$ \\
\hline
\end{tabular}

It is obvious that from Table 2, age with higher prevalence of intestinal parasites in Urban children was between 1-3(40.0) and age 7-9(40.0). A. lumbricoides had higher number of (20.0) at age 1-3 and 7-9, E.histolytica was high at age 1-3, G. lamblia was higher at age 10-12 and T. trichiura only occurred at age 4-6 at (5.3).

Table 3: The age - specific prevalence of intestinal parasite among 58 Suburban children

\begin{tabular}{|l|l|l|l|l|}
\hline Age (years) & $1-3$ & $\mathbf{4 - 6}$ & $\mathbf{7 - 9}$ & $\mathbf{1 0 - 1 2}$ \\
\hline $\begin{array}{l}\text { No of children } \\
\text { investigated }\end{array}$ & $\mathbf{1 8}$ & 12 & $\mathbf{1 6}$ & $\mathbf{1 2}$ \\
\hline No. infected with & & & & \\
\hline A. lumbricoides & $3(17.0)$ & $1(8.3)$ & $2(12.5)$ & $5(41.7)$ \\
\hline Hookworm & $2(11.1)$ & $3(25.0)$ & $2(12.5)$ & $1(8.3)$ \\
\hline G. lamblia & $0(0.0)$ & $1(8.3)$ & $2(12.5)$ & $0(0.0)$ \\
\hline T. trichiura & $0(0.0)$ & $0(0.0)$ & $0(0.0)$ & $2(16.7)$ \\
\hline E. histolytica & $1(5.6)$ & $0(0.0)$ & $0(0.0)$ & $0(0.0)$ \\
\hline Sub total & $6(33.3)$ & $5(41.7)$ & $6(37.5)$ & $8(66.7)$ \\
\hline Absent & $12(66.7)$ & $10(62.5)$ & $10(62.5)$ & $4(33.3)$ \\
\hline Total & $\mathbf{1 8}(\mathbf{1 0 0 . 0})$ & $\mathbf{1 2 ( 1 0 0 . 0 )}$ & $\mathbf{1 6 ( 1 0 0 . )}$ & $\mathbf{1 2 ( 1 0 0 . 0 )}$ \\
\hline
\end{tabular}

It is obvious that from Table 3, age with higher prevalence of Intestinal parasites in suburban area was between age $10-12$ (66.7); A. lumbricoides was higher at age 10 -12 (41.7), Hookworm was higher at age 4 - 6 (25.0); G. lamblia was higher between age $7-9(12.5)$; T. trichiura was higher at age $10-12$ (16.7) and E. histolytica only occurred at age between 1$3(5.6)$.

Table 4: Prevalence of various parasites from Enugu Metropolis (John best, Excel Montisseri and New Haven Primary School)

\begin{tabular}{|l|l|l|l|}
\hline Schools & John Best & Excel Montesseri & New Haven \\
\hline Parasites; & 16 & 14 & 10 \\
\hline A. lumbricoides & $2(12.5)$ & $0(0.0)$ & $3(30.0)$ \\
\hline Hookworm & $0(0.0)$ & $0(0.0)$ & $2(20.0)$ \\
\hline T. trichiura & $0(0.0)$ & $0(0.0)$ & $1(10.0)$ \\
\hline G. lamblia & $1(6.3)$ & $0(0.0)$ & $2(20.0)$ \\
\hline E. histolytica & $1(6.3)$ & $1(7.1)$ & $0(0.0)$ \\
\hline Subtotal & $4(25.0)$ & $1(7.1)$ & $8(80.0)$ \\
\hline Absent & $12(75.0)$ & $13(92.9)$ & $2(20.0)$ \\
\hline Total & $\mathbf{1 6 ( 1 0 0 . 0 )}$ & $\mathbf{1 4 ( 1 0 0 . 0 )}$ & $\mathbf{1 0}(\mathbf{1 0 0 . 0})$ \\
\hline
\end{tabular}


It is obvious that from Table 4, New Haven had a higher prevalence of various parasites (80.0), G. lamblia and E. histolytica had similar value of (6.3) in John Best School while T. trichiura and Hookworm only occurred in New Haven at (10.0) and (20.0) respectively.

Table 5: Prevalence of various parasites from Enugu Metropolis (Community central, Wesley nursery and Primary and Community Primary)

\begin{tabular}{|c|c|c|c|}
\hline Schools & Community Central & $\begin{array}{c}\text { Wesely Nursery \& } \\
\text { Primary }\end{array}$ & $\begin{array}{c}\text { Community Primary } \\
\text { School Ugwumu }\end{array}$ \\
\hline Parasites; & 19 & 19 & 20 \\
\hline A. lumbricoides & $4(21.1)$ & $2(11.0)$ & $5(25.0)$ \\
\hline Hookworm & $4(21.1)$ & $2(11.0)$ & $3(15.0)$ \\
\hline T. trichiura & $1(5.3)$ & $0(0.0)$ & $1(5.0)$ \\
\hline G. lamblia & $1(5.3)$ & $0(0.0)$ & $2(10.0)$ \\
\hline E. histolytica & $0(0.0)$ & $1(5.3)$ & $11(55.0)$ \\
\hline Subtotal & $10(52.6)$ & $4(21.1)$ & $9(45.0)$ \\
\hline Absent & $9(47.4)$ & $15(78.9)$ & $\mathbf{1 9 ( 1 0 0 . 0 )}$ \\
\hline Total & $\mathbf{1 9 ( 1 0 0 . 0 )}$ & $\mathbf{2 0}(\mathbf{1 0 0 . 0})$ \\
\hline
\end{tabular}

It is obvious that from Table 5 that prevalence of various parasites from Enugu Metropolis was higher in Community Primary School Ugwuomu (55.0) and lowest in Wesely Nursery and Primary (21.1). A. lumbricoides was higher in Community Primary School Ugwuomu (25.0); Hookworm was higher in Community Central (21.1); T. trichiura was higher in Community Central (5.3); G. lamblia was higher in Community Primary School Ugwuomu and E. histolytica was higher in wisely Nursery and Primary.

Out of a total of 98 children examined, 10(10.2\%) weighed below normal weight ( $3^{\text {rd }}$ percentile weight), 39(39.8\%) were moderately normal for their weight $\left(3^{\text {rd }}-50^{\text {th }}\right), 45(46.0 \%)$ were normal $\left(51^{\text {st }}-97^{\text {th }}\right)$ and $4(4.1 \%)$ were above normal in both urban and suburban of Enugu metropolis. Children in both urban and suburban have a moderate and normal weight more than those with below or over weight.

Head circumference of $6(6.1 \%)$ children were below normal $\left(3^{\text {rd }}\right.$ percentile $), 50(51.0 \%)$ moderately normal $\left(3^{\text {rd }}-50^{\text {th }}\right)$, $38(39.0 \%)$ were normal $\left(51^{\text {st }}-97^{\text {th }}\right)$ and $4(4.1 \%)$ were above normal. shows the distribution of children in various group (weight and head circumference).

\section{Discussion}

The result of the incidence of parasites in the three (3) study environments of Enugu State (urban) are shown in table 4 .

These percentage incidence of the five parasites in the environment during the study are as follows, Ascaris; New haven primary school 3(30.0\%), John best International school 2(12.5\%), Excel Montisseri 0(0.0\%) Hookworm; N/haven 2(20.0\%), John best 0(0.0\%), Excel Montisseri 0 (0.0\%) G. lamblia; N/haven 2 (20.0\%), John best 1(6.35), Excel Montisseri 0(90.0\%) T. trichiura, $\mathrm{N} /$ haven $1(10.0 \%)$, John best $0(0.0 \%)$, Excel Montisseri $0(0.0 \%)$ E. histolytica, John best 1(6.3\%), Excel Montisseri $1(7.1 \%)$ and $\mathrm{N} /$ haven $0(0.0 \%)$. These findings agreed with the report of [21] that a high prevalence of intestinal parasites is consistent with what is found throughout indigenous population in the suburban tropical areas. The prevalence obtained for intestinal parasites in the Suburban areas of Methodist Primary school, Mbiabon Ikot Udofia in Ini Local government area (LGA) of Southern Nigeria is consistent with $82.6 \%$ obtained by [22]. In some suburban areas of Africa, ignorance, illiteracy, unhealthy socio-cultural religious practices, lack of basic public amenities, poor sanitation, poverty and inadequate access to healthcare are major predisposing factors to intestinal parasitic infections. This study observed the above factors in the suburban community where these schools are located. The 
suburban schools used in the present study lack adequate toilet facility. There is complete absence of potable water, pupil obtain their water from nearby stream and may have been contaminated with fecal matter. Evidently, pupils defecate indiscriminately in the bushes (bush method) around the school premises as observed.

These fecal littering, are likely to contain ova and cyst of parasites. It is possible that the home communities of the urban children are more aware of parasitic infections and have slightly better sanitation and improved personal hygiene than suburban communities. Furthermore, access to health care is within the reach of the urban children. The occurrence of poly parasitism in this study is in line with what results is obtained elsewhere in the tropics and subtropics [22]. The commonest was the co-infection of Ascaris lumbricoides and hookworm. No individual had up to four parasites.

This study also recorded a low degree of malnutrition among the children investigated for intestinal parasitic infection in urban and suburban area of Enugu State.

Though there were low malnutrition, but few with stunting, under weight and overweight, might be due to high prevalence of Ascaris lumbricoides and Hookworm. Ascaris and anthropometric parameters suggest that these helminthes affect the nutritional status of the studied children.

This study does not really show a significant association between nutritional indicators and intestinal parasitic infection especially the protozoan parasites (G. lamblia, E. histolytica), (Similar studies in Tehran and Brazil by [23], recorded a significant association between $\mathrm{G}$. lamblia and nutritional status.

According to [24]. The social economic and physical environment in which an individual lives are major determinant of the degree of association between intestinal parasites and nutritional status.

Although causes of malnutrition are multifactorial intestinal parasitic infections have been associated with impaired growth and stunting in diverse population. There are several mechanisms by which intestinal parasitism may cause or aggravate malnutrition including impaired nutrient absorption resulting from infection and reduced appetite [25].

Adult helminthes worms residing in the small intestine are in an excellent position to interfere with their host nutrition and can induce damage to the intestinal mucosa that may reduce a person's ability to extract and absorb nutrient from food [26]. These factors collectively or singly might have contributed to the malnutrition observed in this study. Ascaris lumbricoides was the most occurred among the five species of human intestinal parasites identified in both urban and suburban of Enugu metropolis school children.

This reveals that the intestinal parasitic infection in children is mostly due to this parasite, though the prevalence was not too high but may increase the chance of malnutrition in children thereby leading to morbidity of children. Therefore, nursery and primary school children, teachers, and nursing mothers should be sensitized on the importance of good hygiene, appropriate sanitation and proper way of feeding children.

Finally, states government should provide basic amenities, more facilities for free immunization and vaccination which would contribute to the elimination of infection and malnutrition among school children especially in suburban area where there is poor environmental and personal hygiene, shortage of clean potable water and indiscriminate defecation (bush method).

Reducing the prevalence of intestinal parasitic infections and malnutrition in school children, may be of tremendous benefit on child growth, development and education outcome.

Funding: Nil

Conflict of interest: Nil

Permission from IRB: Yes

\section{Conclusion}

The study therefore recommends that selective periodic de-worming of school children irrespective of the intensity of the infection for those with high risk of developing parasitism should be considered in other to eradicate parasitism and the risk of malnutrition in Enugu metropolis.

\section{References}

1. Unachukwu M N. The Prevalence of Intestinal Parasitic Infection and Malnutrition. Unpublished Ph.D. Thesis, Anambra State University, Anambra, Nigeria, 21, $24,28,31$.

2. Stephension LS, Latham MC, Ottesen EO. Malnutrition and parasitic helminth infections Parasitology. 2000;121 Suppl:S23-38. 
3. Mitra M and Tiwari A. Malnutrition in preschool children - A study of Brahmin R children - A study of Brahmin Rawat and Teliawat and Telis preschool children of Raipur. Annual conference of Indian society of human genetics $16^{\text {th }}$ and $18^{\text {th }}$ Dec. 1997 xxiii, New Delhi.

4. Nokes $\mathrm{C}$ and Bundy DAP. Compliance and absenteeism in School children: Implications for helminthes control. Trans. R Soc. Trop. Med. Hyg., 87: 148-152. UNICEF, 1998. The state of the world's children. Oxford University Press, New York.

5. Tchuem Tchuenté LA, Behnke JM, Gilbert FS, Southgate VR, Vercruysse J. Polyparasitism with Schistosoma haematobium and soil transmitted helminth infections among school children in Loum, Cameroon. Trop Med Int Health. 2003 Nov;8(11):975-86.

6. Tanner S, Leonard WR, McDade TW, Reyes-Garcia $\mathrm{V}$, Godoy R, Huanca T. Influence of helminthes infections on childhood nutritional status in lowland Bolivia. Am J Hum Biol. 2009 Sep-Oct;21(5):651-6. doi: 10.1002/ajhb.20944

7. Latham MC, and Ottesen EA. Malnutrition and parasitic helminthes infections. Parasitol, 2000;121 Suppl:S 23- 38. 4.

8. Quihui L, Valencia ME, Crompton DW, Phillips S, Hagan P, Morales G, Díaz-Camacho SP.Role of the employment status and education of mothers in the prevalence of intestinal parasitic infections in Mexican rural schoolchildren. BMC Public Health. 2006 Sep $6 ; 6: 225$.

9. Sackey ME, Weigel MM, Armijos RX. Predictors and nutritional consequences of intestinal parasitic infections in rural Ecuadorian children. J Trop Pediatr. 2003 Feb;49(1):17-23.

10. Rodriguez-Morales, A. J., Barbella, R. A., Case, C.,Arria, M., Ravelo, M., Perez, H., Urdaneta, O. Gervasio, G., Rubio, N., Maldonado, A., Aguilera, Y., Viloria, A., Blanco, J. J., Colina, M., Hernandez, E., Araujo, E., Cabaniel, G., Benitez, J., \& Rifakis, P. (2006). Intestinal parasitic infections among pregnant women in Venezuela. Infect Dis Obstet Gynecol, 2006, 23125

11. Savioli L, Bundy D, Tomkins A.. Intestinal parasitic infections: a soluble public health problem. Trans R Soc Trop Med Hyg. 1992 Jul-Aug;86(4):353-4.
12. World Health Organization (WHO). Global Database on Child Growth and Malnutrition: Forecast of Trends.WHO/NHD/00.3. WHO, Geneva. Zaki AM DuPont HL, El Alamy MA, Araest 118:1311-21.

13. Edungbola L D and Obi AA. A Review of human intestinal parasites in Nigeria: challenges and rospects for integrated control. Nigerian Journal of Parasitology. 1992; 13:27-37.

14. Amuta E, Olusi T and Houmsou R. Relationship of intestinal parasitic infections and malnutrition among school children in Makurdi, Benue State- Nigeria. The Internet J. Epidemiol., Vol. 7.

15. Amuta E, Olusi T and Houmsou R. Relationship of intestinal parasitic infections and malnutrition among school children in Makurdi, Benue State- Nigeria. The Internet J. Epidemiol., Vol. 7.

16. Adekunle L. Intestinal parasites and nutritional status of Nigerian children. African Journal of Biomedical Research. 2002; 5:115-119.

17. Okyay P, Ertug S, Gultekin B, Onen O, Beser E. Intestinal parasites prevalence and related factors in school children, a western city sample-Turkey. BMC Public Health, 4: 64-73.

18. Nematia J, Gholamrezanezhad A, Nematian E. Giardiasis and other intestinal parasitic infections in relation to anthropometric indicators of malnutrition: a large-population-based survey of school children in Tehran. Annals of Tropical Medicine and Parasitology. 2008; 102:209-214.

19. Harhay M O, Horton J, Olliaro P L. Epidemiology and control of human gastrointestinal parasites in children. Expert Rev Anti Infect Ther. Feb 2010; 8(2): 219-234.doi: 10.1586/eri.09.119.

20. World Health Organization (WHO). Basic Laboratory Methods in Medical Parasitology. Geneva, Switzerland. World Health Organization; 2000.

21. Hurtado M, Lambourne CA, James P, Hill K, Cheman $\mathrm{K}$, Baca K. Human rights, biomedical science and infectious disease among South American indigenous groups.AnnualReviewofAnthropology.2005;34:639-665

22. Ukpai OM, Ugwu, CD (2003). The prevalence of gastrointestinal tract parasites in primary school children in Ikwuano Local Government Area, Abia State, Nigeria. 
23. Carvalho-Costa FA, Goncalves AQ, Lassance, S L, Silva Neto LM, Salmazo CAA, Boi MN. Giardia lamblia and other intestinal parasitic infections and their relationships with nutritional status in children in Brazilian Amazon. Revista do Instituto de Medicina Tropical de Sao Paulo. 49(3):147-153.9.

24. Assis AMO, Prado MS, Barreto ML, Reis MG, Pinheiro SMC, Parraga IM, Blanton RE. Childhood stunting in northeast Brazil: the role of Schistosoma mansoni infection and inadequate dietary intake.
European Journal of Clinical Nutrition. 2004; 58:10221029.

25. Crompton DW, Nesheim M C. Nutritional impact of intestinal helminthiasis during the human life cycle. Annual Review of Nutrition. 2002; 22:35-59.

26. Opara KN, Udoidung N I. Parasitic Contamination of leafy vegetable. A function of leaf area index. Global Journal of Pure and Applied Science. 9:25-29.

\section{How to cite this article?}

Unachukwu MN, Nwakanma C. Prevalence of Intestinal Parasitic Infection and Malnutrition in Enugu Urban and Suburban Area. Int J Med Res Rev 2014;2(6):565-572. doi:10.17511/ijmrr.2014.i06.10 